\title{
Letrados y literatos en la novelística áurea: El pasajero de Cristóbal Suárez de Figueroa
}

\section{Lawyers and men of letters in the novella of the Golden Age: El pasajero by Cristóbal Suárez de Figueroa}

\section{Mechthild Albert}

https://orcid.org/0000-0002-1414-078X

Rheinische Friedrich-Wilhelms-Universität Bonn

ALEMANIA

malbert@uni-bonn.de

[Hipogrifo, (issn: 2328-1308), 9.2, 2021, pp. 149-161]

Recibido: 08-03-2021 / Aceptado: 03-06-2021

DOI: http://dx.doi.org/10.13035/H.2021.09.02.12

Resumen. Con vistas a agregar un matiz significativo a la relación particular entre letrados y literatura, la presente aportación se enfoca en la miscelánea El pasajero de Cristóbal Suárez de Figueroa (1571-1644), publicada en 1617, aun en los comienzos de la moda novelística. Al encarnar de manera ejemplar el nexo entre "letras" (au sens spécialisé du terme) et "buenas letras"», el autor sirve como punto de partida de la monografía canónica de Jean-Marc Pelorson sobre los letrados castellanos bajo Felipe III (1980). Unos doce años después de la tesis de Pelorson, el sociólogo Pierre Bourdieu arroja nueva luz sobre los literatos del siglo XVII en su estudio pionero Les règles de l'art. Genèse et structure du champ littéraire. El presente artículo, dedicado al análisis del letrado literato en El pasajero se propone enriquecer el punto de vista de Pelorson mediante el aporte de Bourdieu para llegar a una comprensión más compleja y pertinente del letrado áureo y sus ambiciones literarias.

Palabras clave. Letrado; literato; campo literario; Siglo de Oro; Suárez de Figueroa; El pasajero.

Abstract. In order to add a significant nuance to the particular relationship between lawyers and literature, the present contribution focuses on the miscellany $\mathrm{El}$ pasajero by Cristóbal Suárez de Figueroa (1571-1644), published in 1617, even at the beginning of the novelistic fashion. By embodying in an exemplary manner the link between "letras" (au sens spécialisé du terme) et "buenas letras"», the author 
serves as a starting point for Jean-Marc Pelorson's canonical monograph on the Castilian letrados under Philip III (1980). Some twelve years after Pelorson's thesis, sociologist Pierre Bourdieu sheds new light on seventeenth-century literati in his pioneering study Les règles de l'art. Genèse et structure du champ littéraire. The present article, devoted to the analysis of the letrado as a literary author in The Passenger, aims at enriching Pelorson's point of view with Bourdieu's contribution in order to gain a more complex and accurate understanding of the Golden Age lawyer and his literary ambitions.

Keywords. Lawyer; Literate; Literary field; Siglo de Oro/Golden Age; Suárez de Figueroa; El pasajero.

Cuatro jóvenes «que estudiaban más por ambición de sus padres que por necesidad la facultad de los derechos» ${ }^{1}$ deciden abandonar su Alma mater salmantina para trasladarse a la Villa y corte con vistas a fundar allí una academia privada dedicada al cultivo de las artes y letras. La hacienda acaudalada de sus padres les permite realizar su proyecto, de modo que logran sustraerse tanto a la carrera prevista por sus familias como a las exigencias del mercado laboral gracias a su origen aristocrático, dejando sus plazas vacantes a jóvenes de extracción humilde, más necesitados de ganarse la vida y de buscar promoción social a través de una colocación como letrados.

Tal es el planteamiento inicial que sirve de marco a la miscelánea Casa del placer honesto que Jerónimo de Salas Barbadillo publica en 1620. Las implicaciones socioculturales de este dispositivo resultan reveladoras del contexto histórico como ha demostrado Enrique García Santo Tomás (2008) quien ve reflejada aquí la creciente importancia de la educación y la masiva afluencia de los jóvenes a las universidades donde el estudio de leyes y cánones les ofrece una gran diversidad de carreras en el ámbito de la Iglesia y de un Estado con una administración cada vez más burocratizada e influyente ${ }^{2}$. Este proceso se inscribe en un cambio social más amplio marcado, entre otros, por el surgimiento reciente de una élite que Werner Sombart denomina «nueva nobleza urbana» ${ }^{3}$ y que Nieves Romero Díaz (2002) identifica como el milieu en el que nace y al que se dirige la novela corta áurea. La impronta de esta capa entre aristocrática y burguesa se refleja, entre otros, en la relevancia de las profesiones para caracterizar a los personajes que aparecen en las colecciones de novelas y en los respectivos marcos metaficcionales ${ }^{4}$. Así lo demuestran no solo dichos estudiantes de derecho sino también los médicos, teólogos y juristas o letrados que aparecen como narradores o protagonistas en numerosas colecciones de novelas áureas de Cervantes y Suárez de Figueroa, Salas Barbadillo y Castillo Solórzano ${ }^{5}$, entre otros. En todos estos textos llama la atención

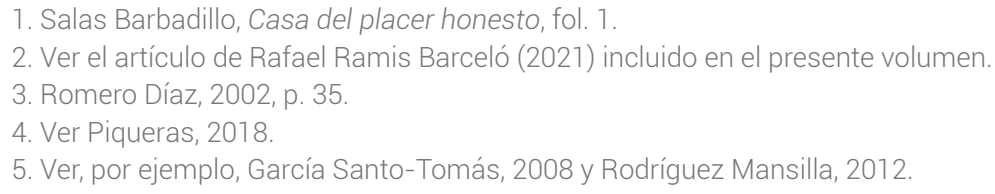


la marcada afinidad entre letrados y literatura, que se remonta al mismo origen etimológico (y social) del letrado, tal como surge en el siglo $\mathrm{XV}^{6}$. A principios del siglo XVII, y al cabo de un vertiginoso aumento de los estudios respectivos, el alto porcentaje de bachilleres, licenciados y doctores en derecho, junto con su polivalente y poco específico perfil profesional (comparado al de médicos y teólogos, por ejemplo), hace de ellos el intelectual por antonomasia, conllevando, sin embargo, el peligro de producir un cierto «proletariado intelectual», antes de quedar substituidos, ya en el siglo XVIII, por los militares en su oficio como funcionarios administrativos del Estado?. En la cumbre del Siglo de Oro, no pocos juristas, que además disponen de la formación retórica propia de su disciplina, cuentan entre los literatos diletantes que frecuentan las academias y, contrariamente a la observación de Jean-Marc Pelorson ${ }^{8}$, el número de personajes juristas no resulta tan exiguo en la narrativa breve, en especial en el subgénero que Willard F. King (1963) Ilama «novela académica» ${ }^{9}$. Tanto Cervantes, en «El licenciado Vidriera» $(1613)^{10}$, como Suárez de Figueroa (1617) se sirven además del personaje del letrado para ilustrar el conflicto entre armas y letras. Más allá de las meras sátiras de oficios al uso ${ }^{11}$, los textos en cuestión contribuyen a negociar el lugar sociocultural del letrado en su circunstancia histórica, caracterizado, entre otros, por una notable permeabilidad y una proximidad, ocasionalmente conflictiva, entre los campos jurídico y literario ${ }^{12}$.

Con vistas a agregar un matiz suplementario a la relación particular entre letrados y literatura, la presente aportación se va a enfocar en un autor y texto sumamente representativos, a saber la miscelánea El pasajero de Cristóbal Suárez de Figueroa ${ }^{13}$, publicada en 1617, es decir pocos años después de las Novelas ejemplares y aun en los comienzos de la moda novelística. El autor, nacido en Valladolid hacia $1571^{14}$ y muerto en Italia hacia 1644, encarna de manera ejemplar el nexo entre letrado y literato, al situarse de «façon assez originale à la croisée entre "letras" (au sens spécialisé du terme) et "buenas letras"» 75 , a tal punto que serviría como punto de partida de la monografía canónica de Jean-Marc Pelorson sobre los letrados castellanos bajo Felipe $1 I^{16}$. Unos doce años después de la tesis de Pelorson, Pierre Bourdieu arroja nueva luz sobre los literatos del siglo XVII en su

6. Ver Pelorson 1980, pp. 15-17 y Estévez Molinero, 2007. Con respecto a su lugar social, Pelorson define a los letrados como «noblesse de robe castillane» que representa precisamente «une couche sociale composite, à dominante "féodale", d'intellectuels citadins».

7. Ver Dedieu, 2005

8. Refiriéndose a la literatura española de la época de Felipe III, Pelorson (1980, p. 367) sostiene que «le personnage du Letrado juriste, sous les diverses formes professionnelles qu'il pouvait présenter (professeur de droit, avocat, juge, magistrat, etc...) y fait une apparition plutôt discrète».

9. Ver Albert, 2019.

10. Ver el artículo de Wolfgang Matzat (2021) incluido en el presente volumen.

11. Ver, por ejemplo, Rodríguez Cacho, 1989

12. Ver, entre otros, Gutiérrez, 2005.

13. Respecto a El pasajero como miscelánea, ver Bradbury, 2016

14. Pelorson 1980, p. 394, refiriéndose a Crawford.

15. Pelorson 1980, p. 391

16. Ver en particular los capítulos «El pasajero et les problèmes d'une autobiographie littéraire» y "L'image de l'écrivain et du "letrado" dans El pasajero». 
estudio pionero Les règles de l'art. Genèse et structure du champ littéraire dedicado a la sociología de la literatura en el siècle classique. El presente estudio, dedicado al análisis del letrado literato en El pasajero se propone enriquecer el punto de vista de Pelorson mediante el aporte de Bourdieu para llegar a una comprensión más compleja y pertinente del letrado áureo y sus ambiciones literarias. Promovido doctor en ambos derechos por la Universidad de Pavia en 159417, Cristóbal Suárez de Figueroa desempeñó a lo largo de su carrera ${ }^{18}$ todo un abanico de cargos jurídicos, entre ellos auditor, abogado fiscal, contrascriptor, juez y comisario ${ }^{19}$. Asimismo fue un literato controvertido por sus críticas mordaces y conocido tanto por sus traducciones del italiano, entre ellas el Pastor fido de Guarini (1590/1602 y 1609) y la Plaza universal de Garzoni (1585/1615), como por sus obras originales, entre las cuales se encuentran la novela pastoril La constante Amarilis (1609) y el texto híbrido del Pasajero (1617).

En este diálogo entre cuatro personajes que viajan a Italia por diversos motivos, se reflejan muy nítidamente los dos polos que son constitutivos para el presente enfoque, a saber la relación entre la jurisprudencia y las bellas letras. La obra, como señala el subtítulo «Advertencias utilísimas a la vida humana» ${ }^{20}$, es de intención didáctica, y está estructurada en diez capítulos titulados «Alivios», que tratan temas de actualidad y de relevancia pública tales como el cambio social, es decir el ascenso de la «nueva nobleza» ${ }^{21}$ y las normas de urbanidad, la religión y la guerra, la justicia y la literatura. Los cuatro personajes, identificados por sus respectivos oficios, son un «maestro en Artes y profesor de Teología», un joven militar llamado don Luis, el platero Isidro y un doctor en «ambas Prudencias» (p. XV) que dirige las conversaciones y en el cual se puede reconocer una proyección del mismo autor. Es ante todo a partir de sus intervenciones que se analizarán sus opiniones y pareceres acerca del letrado y del literato. Aparte de numerosas composiciones poéticas, pues los cuatro son aficionados a la poesía, el diálogo entremezcla los relatos autobiográficos de todos ellos, más el de un ventero pícaro, antiguo conocido del Doctor. Cuando Isidro ha contado su historia hasta el momento presente, don Luis propone que también los demás revelen su pasado, acentuando la manera en que el ingenio individual de cada uno fue formado por el destino:

\footnotetext{
17. Pelorson, 1980, p. 397.

18. Carrera que corresponde en gran medida al modelo presentado por Rafael Ramis Barceló en el presente volumen.

19. Ver Pelorson, 1980, p. 394

20. En el prólogo «Al lector», el autor precisa: «Es mi disinio refrescar las memorias con la fuerza de avisos tan útiles, con la enseñanza de documentos tan necesarios, asestando la artillería de la razón (hecho primero alarde de bueno y malo) contra las torres de propias confianzas» (p. XIII). A continuación, las indicaciones de página entre paréntesis se refieren a la edición Suárez de Figueroa, Cristóbal, El pasajero. Advertencias utilísimas a la vida humana, ed. Francisco Rodríguez Marín, Madrid, Renacimiento, 1913. 21. La «nueva caballería», en términos del autor (pp. 35, 37), así como su estatus, junto con el problema de la movilidad social, se discuten de manera detallada pp. 35-38.
} 
Hagamos pues, si os parece, los tres alarde y muestra general de los impulsos que padecimos, ó, venciendo la corriente de nuestra vocación, ó dejándonos vencer de nuestros incentivos, ya que con tanta llaneza nos declaró Isidro los suyos, significándonos su intención (p. 39).

En opinión del maestro, impresionado por el relato del pícaro ventero, las narraciones (auto)biográficas poseen un eminente valor enciclopédico y didáctico al ilustrar la extrema movilidad social propia de este momento de la temprana modernidad y al brindar orientación a través de recorridos vitales ejemplares -no en el sentido moral sino como muestras de los «maravillosos altibajos» de la virtù, el ingenio y temperamento de cada uno, en pugna con la fortuna, conflicto que se concibe cada vez más en términos de una relación premoderna entre individuo y sociedad:

¡Válgame Dios! Si se pudiesen escribir los sucesos de muchas vidas, iqué silva de varia lección se hallaría en ellas! Maravillosos altibajos había tenido este hombre en la suya hasta entonces: labrador, soldado, religioso, tercero, valiente, bodegonero, y la última dignidad, de quién sólo se podía parar en horca o galera (p. 260).

Por consiguiente, los relatos autobiográficos poseen la función de ofrecer modelos: modelos existenciales de cómo hacer frente a los reveses de fortuna en el sentido de los remedios propuestos otrora por Petrarca (ver Alivio IX), y modelos más específicos de carrera profesional (que también tiene sus reveses). A este respecto resultan particularmente reveladoras las historias del Maestro y del Doctor, pues asignan un lugar destacado al letrado y su puesto en la sociedad, tomando en consideración, asimismo, aspectos pedagógicos y psicológicos que denotan la influencia del Examen de ingenios para las ciencias (1575) de Huarte de San Juan. En este sentido, al final del Alivio I, el Doctor se queja de que, al contrario de los chinos que obligan a sus hijos a seguir la profesión del padre, en Europa se practica la costumbre contraria:

Violéntanse los ingenios, oprimiendo las inclinaciones. Tal vez guían por las letras al que muere por la milicia; tal aplican al arte á quien fuera gran letrado. De aquí nace la perturbación de los ánimos, las rebeldías de las voluntades. Semejante escusa pueden proponer los que dejando su centro, tratan de trasladarse á otro. Hácese historiador el cosmógrafo, astrólogo el boticario, matemático el jurisprudente. Huyen, finalmente, muchos lo en que entraron por fuerza (p. 32).

La formación del Maestro, profesor de Teología, ilustra la versatilidad profesional al pasar por tres etapas, cada una orientada hacia una carrera ejemplar del momento histórico, a saber la medicina, la jurisprudencia y la religión. Hijo de médico, la voluntad paterna le destina a esta profesión, preparada por unos cursos preliminares de Artes y Filosofía en la Universidad de Alcalá. Allí, el joven se aficiona a los placeres de la vida académica, gastando «seis o siete años en deprender imperfectamente algunos principios de latinidad» (p. 100) hasta confesar a su padre 
que la medicina no es lo suyo. Ante la confidencia de su hijo, el mismo progenitor revela su poco interés por la ciencia de Hipócrates - «tiene en mí el arte medicinal un feligrés poco devoto» (p. 107)- aconsejándole, sin embargo, seguir con la carrera para tomársela a la ligera gracias a «alguna cantidad de aforismos y brocárdicos, que en la ciencia médica sirven de lugares comunes» (p. 105), pues «esta vida es toda artificio» (p. 106). Al cabo de esta larga sátira contra los malos médicos, el hijo insiste en su rechazo de la medicina, proponiendo como alternativa a su padre preocupado una carrera de «Leyes y Cánones, profesión noble, ilustre, vida y alma de las ciudades, conservación del mundo» (p. 108) que contribuirá, además, a incrementar el prestigio de la familia en el sentido de la nueva nobleza:

¿Qué médico gusta de no adelantar su casa, de no crecer el timbre de su solar con más lustrosos realces? [...] ¿Podrá haber, pues, tan gran contento para todo nuestro linaje como verme frecuentar las calles de Madrid con la pompa de garnacha, con el boato de oidor? (pp. 108 y ss.).

Ilusionado, y con vistas a convencer a su padre, el joven pinta una carrera fabulosa que avanza rápidamente por varios galardones, del grado a la Cámara, «donde, en entrando, lloverán tan grandes mercedes, que, no sólo será fácil colocarme en perpetua silla occidental o antártica, sino en las mejores audiencias o chancillerías españolas» (p. 109). Apenas persuadido de que los «fines» perseguidos por su hijo son «loables y honrosos», el padre muere inopinadamente, derrumbando así «la estatua de la esperanza mayor» y dejando al joven «lleno de irresolución y ambigüedad» (p. 109). Ante la mera «necesidad» económica opta finalmente por una tercera y última vía, a saber la «facultad de Teología, por el seguro premio que suele alcanzar su eminencia en las oposiciones así de cátedras como de dignidades», dedicándose a los estudios sin la menor vocación religiosa, pero «con el ardor que me infundía el menester» (p. 109). Sus expectativas profesionales se cumplen y va subiendo de escalafón en la jerarquía eclesiástica, «contentísimo por la sombra que hacían mis alas á mi hermana y sobrinos» (p. 110) hasta que brutalmente, en una de las oposiciones, «un criado de cierto obispo y, sin haber abierto un libro en su vida» saca el puesto «en virtud del amparo de su dueño» (p. 110). Como consecuencia de este fracaso decide viajar a Italia -y por eso cuenta entre los pasajeros - para promover su carrera con más ahínco en la misma Roma, «cabeza de la Iglesia [...] y mar profundo, donde las redes de letras y méritos sacan copioso número de diversas remuneraciones, pescados de segura duración» (p. 110).

Por consiguiente, en el relato autobiográfico del Maestro teólogo, la jurisprudencia constituye una carrera influyente entre otras -la que más honores, prestigio social y peso político promete-, frente a la medicina, por una parte, que exige arduos estudios y vocación, y la teología por otra, que obedece más bien a intereses de cobertura financiera. El relato autobiográfico del Maestro propone, por lo tanto, un modelo de carrera(s) académica(s) complementado por la narración retrospectiva del Doctor, alter ego del mismo Suárez de Figueroa. 
El Doctor, personaje central de esta obra, es el pasajero por antonomasia, homo viator marcado por la inconstancia de la humana condición, viajero entre ambas orillas del Mediterráneo hispánico, de destino inestable entre armas y letras, leyes y literatura, marcado por la amargura del desengaño ${ }^{22}$. El «pasajero» dispone de varios saberes - de estudio y erudición libresca los unos, de experiencia vital los otros-, dos vertientes cuya síntesis es considerada como primordial para el buen letrado. En este sentido, él se presenta como graduado de la «facultad de ambas Prudencias, con título de doctor, aunque más docto en experiencia y comunicación de naciones» ( $p . X V)$, favoreciendo con ello los saberes prácticos frente a los teóri$\cos ^{23}$. El Doctor posee una sólida formación humanística, cita a filósofos, literatos y oradores, geógrafos e historiógrafos de la antigüedad y no pierde ocasión para trazar paralelos entre antiqui et moderni. Además, es un experto en comunicación intercultural (como se diría hoy), como lo demuestran los conocimientos sobre la Italia contemporánea, desde Génova hasta Palermo, que transmite a sus compañeros de viaje y que denotan un fondo subjetivo, a pesar de su tinte libresco, confirmando la convicción de «ser el peregrinar provechoso instrumento al uso de las cosas» (p. 1). Asimismo, es versado en literatura y jurisprudencia como lo comprueban, por ejemplo, sus informaciones detalladas sobre la administración del Virreinato de Nápoles, en particular la «Vicaría (que es cárcel y casa de tribunales)» (p. 20). Sus intervenciones monológicas a propósito de letras y leyes parecerían tratados doctos si no fuera por las numerosas opiniones personales expresadas a menudo con una fuerte carga emotiva como son la rabia y la indignación. De acuerdo con el enfoque temático del presente volumen, a continuación se va a tratar más bien someramente al literato para examinar de manera más detallada al letrado.

Muy pronto, el Doctor se da a conocer como aficionado a la literatura y conocedor de su contexto sociocultural, es decir del campo literario, de modo que los Alivios II, III y VIII se consagran casi exclusivamente a las bellas letras. Después de una introducción general al arte poético (pp. 48 y ss.), el Doctor letrado se pronuncia sobre varios temas de actualidad lingüística, literaria y cultural como son el estatus del latín y las traducciones, los extranjerismos y latinismos, revelándose como partidario del ideal estilístico de la claridad, en contra de los oscuros gongorinos. Da una definición de la novela corta en unos términos bien conocidos que iban a volverse canónicos ${ }^{24}$ lamentando asimismo la falta de una literatura historiográfica a la altura de la época. Evidencia la práctica extendida del plagio, las encarni-

22. Ver Pelorson, 1980, pp. 410-412: «La double signification du titre» y, más recientemente, Daguerre, 2017.

23. A este respecto conviene tener en cuenta la observación del Maestro dirigida al orfebre Isidro que, asimismo, constituye un elemento de autorreflexividad con vistas al género de los «alivios»: «[...] la teórica de los libros antes entorpece que adelgaza los ingenios en las cosas comunes, en los términos políticos. La Práctica sí que perficiona la natural viveza, alumbrando en muchas cosas que no se pueden aprender en los estudios. Las conversaciones, sobre todo, afinan la prudencia, maduran los entendimientos y enriquecen los ánimos de infinitos actos nobles» (p. 35).

24. «Es una composición ingeniosísima, cuyo ejemplo obliga a imitación o escarmiento. No ha de ser simple, ni desnuda, sino mañosa y vestida de sentencias, documentos y todo lo demás que puede ministrar la prudente filosofía» (p. 55). 
zadas rivalidades entre literatos, el «trance [...] penoso» del comediógrafo novel que se estrena (p. 82), la servidumbre vergonzante de las dedicatorias, poniendo en guardia contra la excesiva ambición literaria de los diletantes que puede terminar en desengaño, como él mismo lo ha experimentado. Tomando como ejemplo el caso de La constante Amarilis, novela pastoril que Suárez de Figueroa publicó en 1609, el Doctor ilustra las vicisitudes de las obras escritas por encargo, sujetas a la benevolencia de un mecenas. La alienación causada por este tipo de dependencia le lleva incluso a renegar del hijo de su espíritu. El ejemplo de varios diletantes ambiciosos que se ponen en ridículo - desde un «magnífico presbítero» de las Indias que declama su «Poema Antártico» (p. 87) hasta un modesto boticario, pasando por don Cosme de Aldana (hermano del poeta Francisco de Aldana), miembro de la corte de poetas del gobernador de Milán y autor de una «Asneida»-advierte contra la pretensión de «hacerse el roble camueso, águila el ánade, y al fin, hábil y suficiente el idiota incapaz» (p. 94).

Los debates «en pro y contra de la Poesía» (p. 98), en consideración de las específicas condiciones socioculturales, se retoman al final del relato autobiográfico del Doctor (pp. 282 y ss.) donde el testimonio personal del mismo Suárez de Figueroa se hace patente en el episodio apenas velado del rechazo a formar parte de la élite intelectual del duque de Lemos, recién nombrado virrey de Nápoles, maquinado por Argensola 25 . Fracasos como este, provocados por la colisión entre campo literario y campo del poder, que hieren su amor propio, reducen su capital simbólico y hacen peligrar su mismo sustento material, serán precisamente el motivo del exilio voluntario que da origen a su viaje, destinado a alejarle du su «madrastra» de patria (con lo cual se cierra el círculo con el episodio inicial).

Paralelamente a los varios aspectos del campo literario, la representación del letrado y de la jurisprudencia se hace a través del relato autobiográfico del Doctor y de varios discursos críticos dedicados a la justicia y a su administración en España. En la narración de su vida, «que por ser de vida vagabunda podría ser no carezca de novedad» (p. 214) ${ }^{26}$, el 'pasajero' se identifica como hijo de un «gallego de bien» (p. 214), oriundo de La Coruña, modesto letrado cuya falta de «codicia» y ambición deja a su familia en una relativa miseria:

Profesaba Jurisprudencia y el grado de causídico en los tribunales de aquella chancillería, donde fue cobrando tan larga opinión, que, si se valiera del rigor con que hoy se ejerce la abogacía, dejara sus hijos poco necesitados de socorro ajeno (p. 214).

Siguiendo con «débil inclinación» (p. 215) el camino trazado por su padre, el joven estudia primero Gramática, «condenado al remo de los libros» (p. 215), y luego Jurisprudencia, «atend[iendo], con poca gana, por su corto atraimiento, al estudio, antes a la memoria, de las leyes» (p. 215). Es decir que, en principio, ni letras ni leyes constituyen carreras que correspondan a las verdaderas inclinaciones del joven, sino que representan, según parece, un camino trillado que provoca des-

25. Ver Pelorson, 1980, pp. 412-414 así como las páginas correspondientes en Gutiérrez, 2005.

26. Y tomada por varios investigadores como fuente de datos biográficos. 
aliento y enajenación en el alumno. A los 17 años, abandona su «casa y tierra», «deseoso de pasar a Italia» para buscarse la vida, indeciso entre armas y letras ${ }^{27}$, parecido a Tomás Rodaja: «lgnoraba cuál de los caminos había de seguir: letras o armas. Desagrábame mucho la vida militar, su penuria, su asistencia, su penalidad» (pp. 215 y ss.). Decide entonces terminar primero sus estudios doctorándose en leyes para colocarse luego como auditor al servicio de las tropas españolas en Piemonte, combinando así ambas carreras. Cuando se disuelve el ejército no tarda en encontrar «otros puestos de consideración» por «haber servido bien», con «olor de buena voz y fama» (p. 216), hasta que, debido a la muerte de sus padres, vuelve a Valladolid, donde su carrera sufre un terrible estancamiento, pues aparte de las deudas heredadas de sus progenitores se encuentra allí como extranjero en su patria, sin recursos de colocación profesional:

Reconocí más cerrados los medios de cualquier pretensión en mi patria que en la extranjera había hallado en el mayor aprieto. Moríame considerando la estrañeza del proceder, la dificultad de las audiencias, la molestia del esperar, y, sobre todo, la dudosa suerte y cierta dilación en conseguir lo que se pretendiese. Así, no tuve jamás ánimo ni para decir en mi abono una palabra, ni para dar un papel en razón de mi aumento. Para seguir la abogacía faltábame estilo y sobrábame cólera (p. 217).

La narración toma entonces un rumbo picaresco, pues el protagonista pretende «no hall[ar] otro [remedio] sino el de los muchachos aviesos: irse por esos mundos, distraídos y desesperados» (p. 217). Naufragios y devociones, pendencias y amores, prisiones y letras van a marcar los altibajos de una vida en perpetuo movimiento (dando un sentido suplementario al término de «pasajero») que le hace experimentar la otra cara de las leyes en carne propia: de administrador de justicia pasa a ser su víctima. En un primer episodio (pp. 220-225), acusado de homicidio por la falsa denuncia de un harriero, es arrestado y pasa una noche en la cárcel hasta que el Duque, Señor de la comarca, se interesa por su suerte y ordena su liberación. Posteriormente, el antiguo prisionero letrado, ya vestido de la indumentaria propia de su oficio, se encontrará casualmente con el juez, perplejo por descubrir la identidad social de su antiguo preso y por pertenecer al mismo gremio, sorpresa que da un giro burlesco a la anécdota. Ya rehabilitado, el doctor letrado vuelve a Valladolid, donde, en un corro de colegas, entre abogados y jueces, una disputa sobre los malos juristas degenera en cuchillada de modo que el infeliz protagonista, culpable del delito de lesión corporal, se ve obligado a huir, disfrazándose de eclesiástico en sotanilla (pp. 225-228). Después de varias aventuras y amores durante su recorrido angustioso por Andalucía volverá a Madrid -más como literato que como letrado.

La crítica de los letrados, abogados y jueces veniales y carentes de cualificación que se entremezcla a las conversaciones de El pasajero va más allá de los habituales tópicos de la sátira de los oficios por pertenecer el autor, Cristóbal Suá-

27. A este dilema autobiográfico hace de eco la queja ya citada a propósito del conflicto entre la inclinación y los imperativos de la carrera: «Violéntanse los ingenios, oprimiendo las inclinaciones. Tal vez guían por las letras al que muere por la milicia; tal aplican al arte a quien fuera gran letrado. De aquí nace la perturbación de los ánimos, las rebeldías de las voluntades» (p. 32). 
rez de Figueroa, a este mismo gremio y conocerlo desde dentro. En este sentido, la mencionada disputa de Valladolid entre abogados y jueces se enmarca en un discurso crítico que se articula a lo largo del Pasajero, y de manera especial en el Alivio VI (pp. 193-228), que constituye una especie de Elogio y Crítica de la justicia, incluyendo también el relato autobiográfico del Doctor. Frente a la alta estima de la justicia como tal, «tan importante en cualquier república bien gobernada para la salud y paz del género humano» (p. 193), como sostiene el Maestro, el Doctor formula el reproche capital de que las leyes son «trata[das] como á cera [por] los jurisprudentes, declarándolas á su modo, torciéndolas á su interés y arrastrándolas á su intento» (p. 193).

Por una parte, Suárez de Figueroa procura construir en El pasajero el ideal del letrado-magistrado como «representante del pueblo» que «hace [...] bien a todos y agravio a ninguno», «ama[ndo] a los hombres por la justicia» (p. 193). Es justo y busca «el camino de en medio» con «equidad» (p. 193) y «rectitud» (p. 194). Por otra parte, frente a este concepto utópico, los letrados, jueces y abogados se caracterizan, en realidad, por su «soberbia», «altivez» y «arrogancia» (p. 199). A través del personaje del Doctor, el autor letrado critica en particular la «furia [...] tremenda» del «juez primerizo», déspota prepotente, que no solo «anhela por las bolsas de todos» sino que sobre todo «muere por sembrar fuego en su distrito, desnudo de piedad, de consideración, sin Dios, sin ley ni miedo, mientras duran los tres años de su alcaldía o tenientazgo» (p. 196). Por ello, el Doctor portavoz del autor favorece que el oficio de juez sea limitado a un año. También acusa de crueldad y de crimen contra la humanidad a todos los gremios de la jurisdicción, del «carcelero, el procurador, el solicitante, el escribiente» al «abogado, escribano y juez» a los que tilda de «sanguijuelas» y de «perrazos» armados de «colmillos» temibles (p. 196) ${ }^{28}$. Entre los varios niveles jerárquicos de la jurisdicción, cuya cooperación mutua es un principio tan deseable como la harmonía de las diversas cuerdas de un instrumento (p. 195), hay algunos que funcionan mal, en particular los tribunales inferiores donde, lejos de todo control, abundan la arbitrariedad, la corrupción y las extorsiones: «tantos excesos como de contino cometen, por hallarse remotos los castigos» (p. 199). Como remedio a estos abusos el Doctor en ambas leyes propone «hacer secreta pesquisa» (p. 198) aunque esta también tuviera sus inconvenientes. Otro punto crítico son las «larguísimas resoluciones» de las causas «así civiles como criminales» (p. 340), dilación de la que son responsables todos los implicados, tanto «escribanos y procuradores» como, sobre todo, los jueces. Para poner remedio a estas deficiencias convendría, según el Doctor, reflejo ficcional de Suárez de Figueroa, que los jueces, aparte de su formación teórica, dispongan de una importante experiencia práctica que haya formado su carácter:

28. Resulta sorprendente que, en esta diatriba contra los malos letrados, Suárez de Figueroa se refiera a «Pedro Blesense» (p. 196; 1135-1211), secretario real en Sicilia y en la Inglaterra de Enrique II, después de haber estudiado leyes y teología en Boloña y París. 
Desto se infiere convenir para su breve expedición se desvele el príncipe en la elección de jueces. No basta sean letrados de buena intención, costumbres y vida, sino también astutos, sagaces, pláticos y sabedores de infinitas circunstancias, dobleces y malicias, que no se aprenden en los libros, estando encerrados en los estudios (p. 341)

No carece de interés que, después de la guerra y la justicia como «los dos requisitos del buen gobierno» (p. 199), el narrador mencione un tercer aspecto, a saber la «provisión» de vituallas como son el trigo, «carne, tocino, aceite, carbón, sal y cosas así» y su justa distribución a buen precio (p. 200). Este oficio de alta responsabilidad «es propio del regidor, hombre público, puesto en aquel cargo como mayordomo de la ciudad ó villa» (p. 200), que regenta «[l]a república de la Plaza Mayor» (p. 202). En este contexto, el Doctor legista relata un «contezuelo» autobiográfico que, junto con la pendencia de Valladolid, arroja una luz bastante dudosa sobre su propio concepto de la justicia. Al sentirse tratado de manera poco respetuosa por una verdulera que le pide, además, un precio exagerado, la sigue de noche cuando vuelve a casa, golpeándola de manera salvaje. Aparte de unas leves dudas alegadas por el Maestro, los demás integrantes del grupo no pronuncian ningún tipo de escrúpulo frente a esta actuación.

Un último aspecto que constituye el común denominador entre el letrado y el literato nos facilita la clave del doble fracaso de Suárez de Figueroa, observado por Pelorson bajo los títulos «Le rêve d'une création littéraire mieux respectée» y «L'amertume du letrado» ${ }^{29}$. A este respecto, las preocupaciones autobiográficas reflejadas a nivel literario en El pasajero confirman los datos documentales analizados por el historiador francés. Se trata de la situación de competencia y rivalidad en una sociedad marcada por la movilidad social y el ascenso de hominis novi. Esta competitividad se da tanto en el ámbito profesional de los letrados como en el emergente campo literario. Suárez de Figueroa, él mismo de origen más bien modesto, se lamenta amargamente en El pasajero «desta edad en que triunfan tanto los indignos» (p. 25) y la «baja sangre» (pp. 36 y ss.), maldiciendo la «nueva» (p. 38) o «moderna caballería» (p. 317), o sea «estos nuevos pájaros de caballería» (p. 321), y llamando la atención sobre las molestas consecuencias de «la improvisa mudanza de una esfera a otra» (p. 36). Tanto respecto al campo literario que se está formando (p. 282) como respecto al jurídico (p. 288), el narrador se queja del éxito de los ignaros debido a relaciones de patronazgo con los poderosos. En este contexto social parece considerarse a sí mismo en la situación «odios[a]» de un eterno «pretensor» (p. 2), rechazado en el umbral de la gloria (tal como lo hace patente también el episodio arriba mencionado del conde de Lemos) y cuyo orgullo le impide entrar en el juego depreciable, actitud que él presenta como carencia de «codicia y ambición» (p. 2), despreocupación (afectada) que culmina en su «negligencia en 
no haber dado sobre alguna pretensión ni un papel, alegando servicios y estudios» (p. 2). El Maestro comenta como sigue este trance inextricable que el Doctor no es el único en experimentar, mostrándose comprensivo con la actitud resignada, pero moralmente superior del que prefiere no mezclarse de la baja lucha entre rivales:

Muchos se quedan atrás y renuncian cualesquier mejoras, por no engolfarse en las descortesías, en las dificultades de audiencias, en las asperezas de ministros y en los profundos piélagos de pretensiones (p. 2).

Ante la situación de competencia y rivalidad marcada por la influencia omnipresente y decisiva del campo de poder, que se le plantea igual como letrado que como literato, el doctor opta por el destierro voluntario. A través del «pasajero» que transita entre España e Italia, entre letras y leyes, en busca del éxito y renunciando a él tras no encontrarlo para no someterse a la lógica del mercado, Suárez de Figueroa ha creado un personaje representativo que, precisamente por su posición marginal y fronteriza, permite una mirada crítica a la sociedad de su tiempo y a la plaza que el letrado ocupa en ella. Asimismo, su obra miscelánea El pasajero contribuye a la circulación de un conjunto de saberes idiosincráticos, tanto librescos como existenciales, propios de un letrado literato del Siglo de Oro.

\section{BibliografíA}

Albert, Mechthild, «De bachilleres y graduados: Alonso de Castillo Solórzano y la novela académica en el contexto del campo literario», Criticón, 135, 2019, pp. 113-129.

Bourdieu, Pierre, Las reglas del arte. Génesis y estructura del campo literario, Barcelona, Anagrama, 2005.

Bradbury, Jonathan David, The Miscellany of the Spanish Golden Age. A Literature of Fragments, London, Routledge, 2016.

Daguerre, Blandine, Passage et écriture de l'entre-deux dans «El Pasajero» de Cristóbal Suárez de Figueroa, Thèse de doctorat, Pau, Université de Pau et des Pays de l'Adour, 2017.

Dedieu, Jean-Pierre, «La muerte del letrado», en Letrados, juristas y burócratas en la España moderna, coord. Francisco José Aranda, Cuenca, Universidad de Castilla-La Mancha, 2005, pp. 479-512.

Estévez Molinero, Ángel, «"La corona de los prudentes letrados": canonizaciones en el siglo XV"», Bulletin Hispanique, 109, décembre 2007, pp. 401-419.

Gutiérrez, Carlos Manuel, La espada, el rayo y la pluma. Quevedo y los campos literario y de poder, West Lafayette, Purdue University Press, 2005.

King, Willard F., Prosa novelística y academias literarias en el siglo XVII, Madrid, BRAE (Anexo X), 1963. 
Matzat, Wolfgang, «El destino de un letrado. Reflexiones en torno a la novela cervantina El licenciado Vidriera», Hipogrifo. Revista de literatura y cultura del Siglo de Oro, 9.2, 2021, pp. 137-148.

Pelorson, Jean-Marc, Les «Letrados», juristes castillans sous Philippe III. Recherches sur leur place dans la société, la culture et l'état, Poitiers, Université de Poitiers, 1980.

Piqueras, Manuel, Salas Barbadillo y las colecciones de metaficciones. La literatura en el abismo, Vigo, Editorial Academia del Hispanismo, 2018.

Ramis Barceló, Rafael, «La carrera académica de los letrados en el Barroco hispano», Hipogrifo. Revista de literatura y cultura del Siglo de Oro, 9.2, 2021, pp. 75-92.

Rodríguez Cacho, Lina, Pecados sociales y literatura satírica en el siglo XVI: los «Coloquios» de Torquemada, Madrid, Ediciones de la Universidad Autónoma de Madrid, 1989.

Rodríguez Mansilla, Fernando, «Un Quijote culterano: El culto graduado de Alonso de Castillo Solórzano», Bulletin of Hispanic Studies, 89.4, 2012, pp. 331-345.

Romero-Díaz, Nieves, Nueva nobleza, nueva novela: reescribiendo la cultura urbana del barroco, Newark, Juan de la Cuesta, 2002.

Salas Barbadillo, Alonso Jerónimo de, Casa del placer honesto, Madrid, Viuda de Cosme Delgado, 1620.

Suárez de Figueroa, Cristóbal, El pasajero. Advertencias utilísimas a la vida humana, ed. Francisco Rodríguez Marín, Madrid, Renacimiento, 1913.

Suárez de Figueroa, Cristóbal, El pasajero. Advertencias utilísimas a la vida humana, ed. Enrique Suárez Figaredo, Lemir, 22, 2018, pp. 355-648. 